Document downloaded from:

http://hdl.handle.net/10251/46933

This paper must be cited as:

Robles Martínez, A.; Ruano García, MV.; Ribes Bertomeu, J.; Ferrer, J. (2013). Factors that affect the permeability of commercial hollow-fibre membranes in a submerged anaerobic MBR (HF-SAnMBR) system. Water Research. 47(3):1277-1288. doi:10.1016/j.watres.2012.11.055.

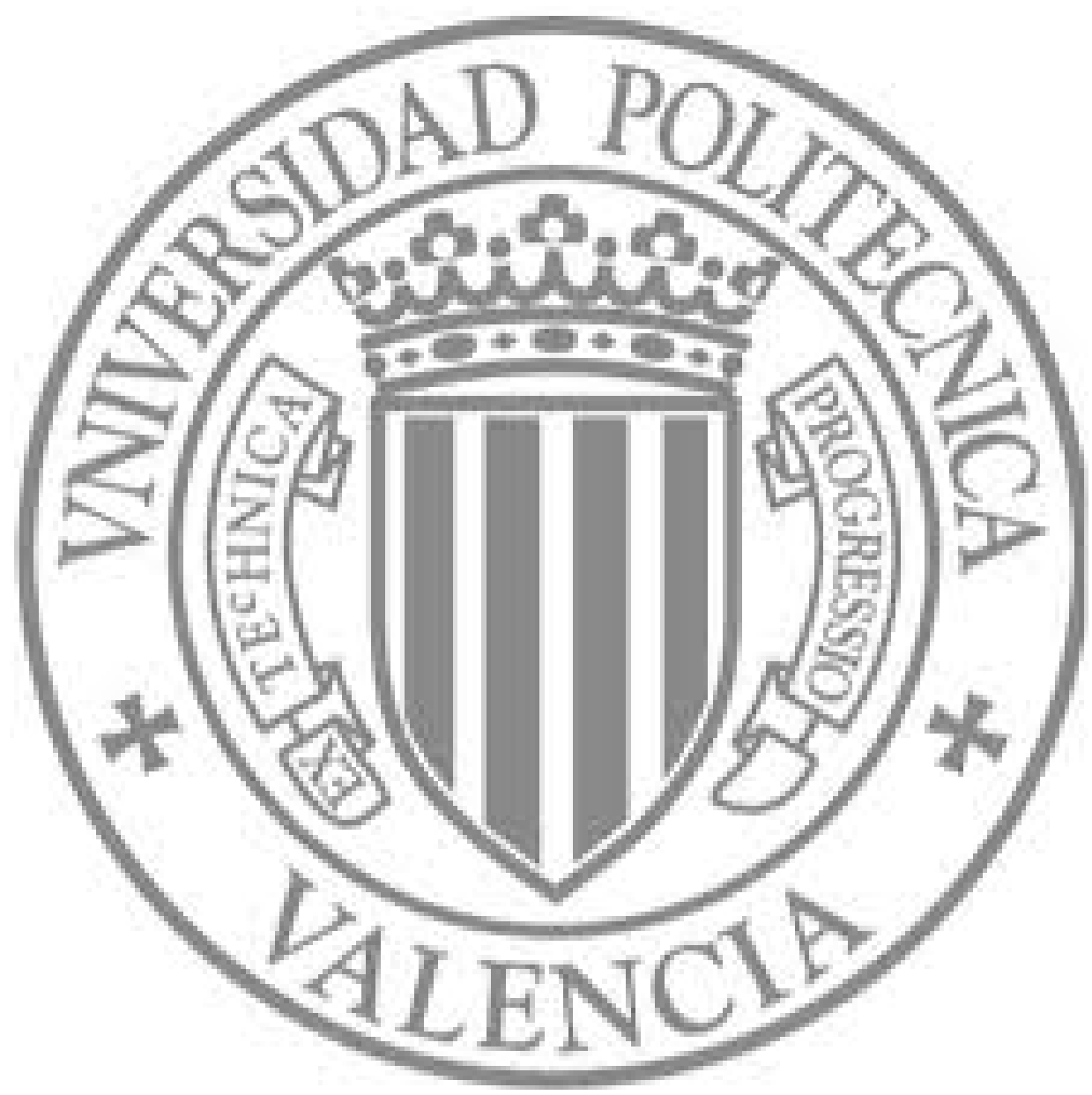

The final publication is available at

http://dx.doi.org/10.1016/j.watres.2012.11.055

Copyright Elsevier 
1

\section{Factors that affect the permeability of commercial hollow-fibre membranes in a submerged anaerobic MBR (HF-SAnMBR) system}

\author{
A. Robles ${ }^{\mathrm{a}^{*}}$, M.V. Ruano ${ }^{\mathrm{b}}, \mathrm{J}_{\text {. Ribes }}{ }^{\mathrm{b}}$, and J. Ferrer ${ }^{\mathrm{a}}$
}

${ }^{a}$ Institut Universitari d'Investigació d'Enginyeria de l'Aigua i Medi Ambient, IIAMA, Universitat Politècnica de València, Camí de Vera s/n, 46022, Valencia, Spain (e-mail: ngerobma@upv.es; jferrer@hma.upv.es)

${ }^{\mathrm{b}}$ Departament d'Enginyeria Química, Escola Tècnica Superior d'Enginyeria, Universitat de València, Avinguda de la Universitat s/n, 46100, Burjassot, Valencia, Spain (e-mail: m.victoria.ruano@uv.es; josep.ribes@uv.es)

* Corresponding author: tel. +34 9638799 61, fax +34 9638790 09, e-mail: ngerobma @upv.es 

submerged anaerobic membrane bioreactor; membrane permeability.

36

\section{Introduction}

38

1.1. Anaerobic treatment of urban wastewater using MBR technology

40 anaerobic treatment of urban wastewater at ambient temperatures. This interest focuses on the sustainable advantages of anaerobic rather than aerobic processes, i.e. anaerobic processes generate little sludge due to the low anaerobic biomass yield; consume little energy because no aeration is needed; and generate biogas that can be used as an energy resource. The total greenhouse gas emissions of this technology are, therefore, low because low energy consumption indirectly means low gas emissions. The main challenge of anaerobic biotechnology is to develop treatment systems that prevent biomass loss and enable high sludge retention times (SRTs) in order to offset the low growth rates of anaerobic biomass at ambient temperatures (Lin et al., 2010). In this respect, submerged anaerobic membrane bioreactors (SAnMBRs) are a promising technology for urban wastewater treatment. However, operating membrane bioreactors with high SRTs may lead to high mixed liquor total solids (MLTS) at a specific reacting volume. This is one of the main constraints of using membranes (Judd and Judd, 2011) since it can result in high membrane fouling propensities.

\subsection{Membrane fouling in SAnMBRs}


The key challenge in SAnMBR technology is how to optimise membrane operating

in order to minimise any kind of membrane fouling, especially the irrecoverable/permanent component that cannot be eliminated by chemical cleaning. The extent of irrecoverable/permanent fouling is what ultimately determines the membrane lifespan (Judd, 2008; Drews, 2010a; Patsios and Karabelas, 2011). Several strategies to control fouling (see, for example, Liao et al., 2006) aim to optimise filtration whilst minimising investment and operating costs. In this respect, the SAnMBR design strategy must be carefully selected. Depending on the design strategy, different design criteria can be adopted. One such criterion is based on operating membranes in sub-critical filtration conditions that are limited by the so-called critical flux $\left(\mathrm{J}_{\mathrm{C}}\right)$ (Bachin et al., 1995; Field et al., 1995). Operating membranes sub-critically gives membranes long lifespans, which reduces replacement and maintenance costs (by minimising physical cleaning costs, i.e. membrane scouring or back-flush). In this respect, MLTS has been widely identified as one of the factors that affect $\mathrm{J}_{\mathrm{C}}$ most. Thus, an investment compromise between operating reactor volume and filtration area should be selected in order to keep MLTS at subcritical levels for a given transmembrane flux (J). Another design criterion is based on operating membranes at critical or supra-critical filtration conditions. This reduces initial investment costs because it requires lower operating volumes and/or lower membrane surfaces than when operating membranes at sub-critical filtration conditions, however, replacement, maintenance and operating costs are probably higher. filtration conditions (Drews et al., 2010b) are most suitable in order to optimise the membrane module design and configuration. An exhaustive analysis in the different potential operating conditions is, therefore, necessary in order to optimise both membrane lifespan (i.e. membrane replacement cost) and operating and maintenance costs (i.e. the 
cleaning mechanism). In this respect, it is necessary to assess the impact of the main operating variables upon membrane performance, i.e. frequency and duration of the physical cleaning stages (back-flush and relaxation); gas sparging intensity; cross-flow sludge velocity over the membrane surface (for cross-flow membrane configurations); up-flow sludge velocity in the membrane tank (submerged membrane configurations) which determines the sludge concentration factor when the membranes are located in external tanks; and maximum operating transmembrane pressure (TMP).

\subsection{Full-scale implementation of SAnMBRs}

Membrane technology has been used increasingly to treat wastewater over the last decade (Lesjean and Huisjes, 2007) even in large urban WWTPs. The treatment capacity of urban MBR WWTP has significantly increased (to maximum design flow rates of more than $150000 \mathrm{~m}^{3}$ day $^{-1}$ ) in just a few years (Huisjes et al., 2009). As regards membrane configuration, flat sheet (FS) membranes are used mostly in small plants $(<$ $5000 \mathrm{~m}^{3} \mathrm{~d}^{-1}$ ), whilst hollow fibre (HF) membranes are used for the entire flow range and prevail in large plants (> $\left.10000 \mathrm{~m}^{3} \mathrm{~d}^{-1}\right)$ and account for about $75 \%$ of all total MBR installed capacity (Cote et al., 2012).

Nevertheless, it is important to highlight that all these urban MBR WWTPs are aerobic wastewater treatments. Although MBR technology has not yet been applied to full-scale anaerobic urban wastewater treatment, the scientific community is showing increasing interest in the feasibility of its full-scale implementation because of the abovementioned advantages. Indeed, several studies which assess the feasibility of using SAnMBR technology to treat urban wastewater at the laboratory scale have been published (Jeison and van Lier, 2007; Huang et al., 2008; Lew et al., 2009). However, the 
111 impact of the main operating conditions upon membrane fouling cannot be determined

112 exactly at the lab scale because they depend heavily on the membrane size. In HF

113 membranes in particular, HF length is a key performance parameter. In this respect, there

114 is still a lack of thorough knowledge about fouling mechanisms, mainly as regards

115 hydraulic performance and membrane permeability (Guglielmi et al., 2007; Di Bella et

116 al., 2010; Mannina et al., 2011). In addition, it is expected that membrane fouling will be

117 affected to a considerable degree by the different characteristics of aerobic and anaerobic

118 mixed liquors, such as particle size distribution, extracellular polymeric substances

119 (EPS), soluble microbiological products (SMP), biomass concentration, inorganic and

120 organic compounds (Lin et al., 2009), or pH values affecting both biofouling (Sweity et

$121 a l ., 2011)$ and formation of chemical precipitates.

122

Therefore, since membrane performance cannot be scaled up directly from laboratory to plant dimensions, especially in the case of HF-based technology (Liao et al., 2006), further studies of HF-SAnMBR technology on an industrial scale are needed in order to facilitate its design and implementation in full-scale wastewater treatment plants

\section{7 (WWTPs).}

To gain more insight into the optimisation of the physical separation process in a SAnMBR system at the industrial scale, this paper shows the impact of the main operating variables upon the performance of industrial HF membranes. Gas sparging intensity, up-flow sludge velocity in the membrane tank, duration and frequency of the different physical cleaning stages (relaxation and back-flush), and length of filtration stage were evaluated in an SAnMBR system featuring commercial HF membrane modules. The effect of these variables at two different membrane operating conditions (sub-critical and critical/supra-critical filtration conditions) was assessed. The plant was 
operated using Carraixet WWTP pre-treatment effluent (Valencia, Spain). On the basis of the results obtained this study aims to provide guidelines for the sub-critical and critical operation of commercial HF membranes in an SAnMBR system.

\section{Materials and methods}

\subsection{Demonstration plant description}

Figure 1 shows the flow diagram of the HF-SAnMBR demonstration plant used in this study. It consists mainly of an anaerobic reactor with a total volume of $1.3 \mathrm{~m}^{3}\left(0.4 \mathrm{~m}^{3}\right.$ head space) connected to two membrane tanks each with a total volume of $0.8 \mathrm{~m}^{3}\left(0.2 \mathrm{~m}^{3}\right.$ head space). Each membrane tank has one industrial HF ultrafiltration membrane unit (PURON $^{\circledR}$, Koch Membrane Systems (PUR-PSH31) with $0.05 \mu$ m pores). Each module has $9 \mathrm{HF}$ bundles, $1.8 \mathrm{~m}$ long, giving a total membrane surface of $30 \mathrm{~m}^{2}$. Normal membrane operating entails a specific schedule involving a combination of different individual stages taken from a basic filtration-relaxation (F-R) cycle. In addition to traditional membrane operating stages (filtration, relaxation and back-flush), another two stages of membrane operation were considered: degasification and ventilation.

$$
\text { For further details of this SAnMBR demonstration plant see Giménez et al. (2011) }
$$
and Robles et al. (2012a).

\subsection{Operating conditions}

The demonstration plant was fed with effluent from pre-treatment of a full-scale WWTP (screening, degritter, and grease removal), which main component is domestic 
163

164

165

166

167

168

169

170

171

172

173

174

175

176

177

178

179

180

181

182

183

184

185

186

187

188

type. It is important to emphasise the great variation in the characteristics of the anaerobic reactor influent (e.g. $186 \pm 61 \mathrm{mg} \mathrm{L}^{-1}$ of TSS and $388 \pm 95 \mathrm{mg} \mathrm{L}^{-1}$ of total COD), which is reflected by the high standard deviation of each parameter. The plant was operated using an SRT of 70 days on operating days 1 to 445, and an SRT of 40 days on operating days 446 to 600 . Hydraulic retention times (HRTs) ranged from 5 to 24 hours. The temperature varied from around 33 to $15^{\circ} \mathrm{C}$. The $\mathrm{pH}$ of the mixed sludge ranged from 6.5 to 7.1 , and carbonate alkalinity remained at values of around $600 \mathrm{mgCaCO}_{3} \mathrm{~L}^{-1}$.

We studied how membranes operate in both short-term trials and in the long term. In the latter instance, the membrane underwent 300 -second basic F-R cycles ( $250 \mathrm{~s}$ filtration and 50 s relaxation) with 30 seconds of back-flush every 10 cycles, 40 seconds of ventilation every 10 cycles, and 30 seconds of degasification every 50 cycles. In addition, six different $\mathbf{J}_{20}$ and temperature conditions were tested: $13.3,10,12,13.3,11$ and 9

$\mathrm{LMH}$, at controlled temperatures of $33,33,25$, and $20^{\circ} \mathrm{C}$, spring and summer ambient temperatures (from approx. 20 to $30^{\circ} \mathrm{C}$ ), and autumn and winter ambient temperatures (from approx. 30 to $14{ }^{\circ} \mathrm{C}$ ), respectively. Hence, the overall operating period was divided into six experimental periods (periods $\mathrm{i}$, ii, iii, iv, $\mathrm{v}$ and vi) taking into account both $\mathrm{J}_{20}$ and temperature. The average specific gas demand per membrane area $\left(\mathrm{SGD}_{\mathrm{m}}\right)$ was 0.23 $\mathrm{Nm}^{3} \mathrm{~h}^{-1} \mathrm{~m}^{-2}$. A maximum TMP safety value of 0.4 bars was set. The flow of sludge through the membrane tank was set to $2700 \mathrm{~L} \mathrm{~h}^{-1}$, giving an up-flow sludge velocity of $2.7 \mathrm{~mm} \mathrm{~s}^{-1}$

In order to evaluate the critical filtration conditions throughout the long-term membrane performance, different short-term trials (flux-step type, see Robles et al., 2012a) were carried out. For instance, on day 125 and day 590 (operating with MLTS of $23 \mathrm{~g} \mathrm{~L}^{-1}$ and $\mathrm{SGD}_{\mathrm{m}}$ of $0.23 \mathrm{Nm}^{3} \mathrm{~h}^{-1} \mathrm{~m}^{-2}$ ), the critical flux resulted in 14 and $10.5 \mathrm{LMH}$, 
189

190

191

192

193

194

195

196

197

198

199

200

201

202

203

204

205

206

207

208

209

210

211

212

213

214

respectively. Therefore, the critical flux remained generally at values over $10.5-14$

LMH during the operating period since $\mathrm{SGD}_{\mathrm{m}}$ was maintained at $0.23 \mathrm{Nm}^{3} \mathrm{~h}^{-1} \mathrm{~m}^{-2}$ and

MLTS remained mostly below $23 \mathrm{~g} \mathrm{~L}^{-1}$. Hence, the long-term operating shown in this study was mainly carried out at sub-critical filtration conditions ( $\mathbf{J}_{20}$ was varied from 9 to 13.3 LMH).

In addition, several short-term trials were conducted at sub-critical and supra-critical filtration conditions with varying gas sparging intensities, up-flow sludge velocities in the membrane tank, durations and frequencies of the different physical cleaning stages (relaxation and back-flush), and lengths of filtration. Normally, the membrane was operated with 300-second basic F-R cycles (250 s filtration and $50 \mathrm{~s}$ relaxation), 30 seconds of back-flush every 10 cycles, 40 seconds of ventilation every 10 cycles, and 30 seconds of degasification every 50 cycles, whilst the operating $\mathbf{J}_{20}$ was $10 \mathrm{LMH}$, the average $\mathrm{SGD}_{\mathrm{m}}$ was $0.23 \mathrm{Nm}^{3} \mathrm{~h}^{-1} \mathrm{~m}^{-2}$, and the up-flow sludge velocity was $2.7 \mathrm{~mm} \mathrm{~s}^{-1}$. Table 1 summarises the values of the operating variables studied in each short-term trial. In each trial, the sub-critical and supra-critical conditions were determined by the different levels of MLTS. The $\mathbf{J}_{20}$ in these short-term trials was set to $10 \mathrm{LMH}$, whilst the other operating variables of the membrane operating mode were established in the same way as the general, long-term operating conditions mentioned above.

\subsection{Analytical methods}

\subsubsection{Analytical monitoring}

In addition to the on-line process monitoring, the performance of the biological process was assessed by taking 24-hour composite samples of the influent and effluent 
streams, and taking grab samples of anaerobic sludge once a day. The following

216 parameters were analysed daily: total solids (TS); total suspended solids (TSS); volatile

217 suspended solids (VSS); carbonate alkalinity; and nutrients (ammonium $\left(\mathrm{NH}_{4}-\mathrm{N}\right)$ and

218 orthophosphate $\left.\left(\mathrm{PO}_{4}-\mathrm{P}\right)\right)$. The total and soluble chemical oxygen demand $\left(\mathrm{COD}_{\mathrm{T}}\right.$ and

$219 \mathrm{COD}_{\mathrm{S}}$, respectively) were determined once a week.

220

221

Solids, COD, and nutrients were determined according to Standard Methods (2005).

222 Carbonate alkalinity was determined by titration according to the method proposed by

223 WRC (1992).

224

225

\subsubsection{Membrane performance indices}

226

The $20^{\circ} \mathrm{C}$-normalised membrane permeability $\left(\mathrm{K}_{20}\right)$ was calculated using a simple

filtration model (Equation 1) that takes into account the TMP and J data monitored

online. This simple filtration model includes temperature correction (Equation 2) to account for the dependence of permeate viscosity on temperature (Rosenberger et al., 2006), and therefore the $20^{\circ} \mathrm{C}$-normalised transmembrane flux $\left(\mathrm{J}_{20}\right)$ was calculated by applying Equation 3. Relative membrane permeability $\left(\mathrm{K}_{0}\right)$ was used to assess the effect of the different operating factors on membrane performance. This relative permeability was defined as shown in Equation 4. Total membrane resistance $\left(\mathrm{R}_{\mathrm{T}}\right)$ was theoretically represented by the following partial resistances (Equation 5): membrane resistance $\left(\mathrm{R}_{\mathrm{M}}\right)$; cake layer resistance $\left(\mathrm{R}_{\mathrm{C}}\right)$; irreversible layer resistance $\left(\mathrm{R}_{\mathrm{I}}\right)$; and irrecoverable layer 237 resistance $\left(\mathrm{R}_{\mathrm{IC}}\right)$.

$$
K_{20}=\frac{J_{T} f_{T}}{T M P}
$$


$241 \quad J_{20}=J_{T} \cdot \exp (-0.0239(T-20))$

$242 \quad K_{0}(t)=\frac{K_{20}(t)}{K_{20}(t=0)}$

Moreover, $\mathrm{J}_{\mathrm{C}}$ was determined by applying a modified flux-step method based on the method proposed by van der Marel et al. (2009). $\mathrm{J}_{\mathrm{C}}$ was calculated according to its weak concept: the flux below which TMP and $\mathrm{J}$ are not directly related. When applying this method, the duration of both filtration and relaxation stages was set to $15 \mathrm{~min}$. Fluxstepping was arbitrarily set to $1.22 \mathrm{LMH}$ of $\mathrm{J}_{20}$ (equivalent to a permeate flow rate of 50

$\mathrm{L} \mathrm{h}^{-1}$ ). The relaxation stages were conducted using the same $\mathrm{SGD}_{\mathrm{m}}$ as in the filtration

\section{Results and discussion}

\subsection{Long-term performance}

Figure 2 depicts the average daily $\mathrm{K}_{20}$ (Figure $2 \mathrm{a}$ ) and the average daily $\mathrm{R}_{\mathrm{T}}$ (Figure 2b) obtained during the operating period, and the average daily MLTS in the anaerobic sludge entering the membrane tank. It must be said that the MLTS level in the membrane tank increased by up to $5 \mathrm{~g} \mathrm{~L}^{-1}$, depending on the ratio between the net permeate flow rate and the sludge flow rate entering the membrane tank. The results shown in Figure 2 can be divided in two different long-term operating periods according to the irreversible/ 263 irrecoverable fouling component observed: (1) days 1 to 300; and (2) days 300 to 600. It 
is important to note that since no chemical cleaning was conducted throughout the operating period, it was not possible to determine the single contribution to $R_{T}$ of both $R_{I}$ and $\mathrm{R}_{\mathrm{IC}}$.

Up to operating day 300 , no significant irreversible/irrecoverable fouling was observed, since $K_{20}$ and $R_{T}$ recovered to values very close to the values obtained at the beginning of the long-term operation as MLTS decreased. This behaviour indicated that throughout this operating period, $R_{T}$ was mainly related to $R_{C}\left(R_{I}\right.$ was negligible), whilst a relatively constant contribution of about $5 \cdot 10^{11} \mathrm{~m}^{-1}$ (at $650 \mathrm{LMH} \mathrm{bar}{ }^{-1}$ of $\mathrm{K}_{20}$ treating clean water in similar operating conditions) was attributed to $R_{M}$. This behaviour means that the MLTS level is a key factor as regards membrane permeability in this HFSAnMBR system (Robles et al., 2012b). In this respect, Figure 2a illustrates how every variation in MLTS was inversely reflected by $\mathrm{K}_{20}$. Nevertheless, it is important to note that even at high MLTS levels (up to $25 \mathrm{~g} \mathrm{~L}^{-1}$ ) and relatively low $\mathrm{SGD}_{\mathrm{m}}$ values (around $0.23 \mathrm{Nm}^{3} \mathrm{~h}^{-1} \mathrm{~m}^{-2}$ ), $\mathrm{K}_{20}$ and $\mathrm{R}_{\mathrm{T}}$ remained at sustainable values, above $100 \mathrm{LMH} \mathrm{bar}^{-1}$ and below $3 \cdot 10^{12} \mathrm{~m}^{-1}$, respectively. At MLTS of more than $25 \mathrm{~g} \mathrm{~L}^{-1}, \mathrm{~K}_{20}$ showed fell sharply because the $20^{\circ} \mathrm{C}$-normalised $\mathrm{J}_{\mathrm{C}}$ was exceeded: 10 and $13 \mathrm{LMH}$ when operating at 0.23 $\mathrm{Nm}^{3} \mathrm{~h}^{-1} \mathrm{~m}^{-2}$ of $\mathrm{SGD}_{\mathrm{m}}$ and MLTS levels of 28 and $23 \mathrm{~g} \mathrm{~L}^{-1}$, respectively (close to the operating membrane fluxes). Thus, at MLTS levels higher than $25 \mathrm{~g} \mathrm{~L}^{-1}$, an $\mathrm{SGD}_{\mathrm{m}}$ of 0.23 $\mathrm{Nm}^{3} \mathrm{~h}^{-1} \mathrm{~m}^{-2}$ was not enough to maintain sub-critical filtration conditions.

After operating day 300, a slight downward trend in $\mathrm{K}_{20}$ and a slight upward trend in $\mathrm{R}_{\mathrm{T}}$ were observed even when operating at a more or less stable MLTS level (see period day 300 to 400). This behaviour revealed a progressive accumulation of irreversible/irrecoverable fouling over the membrane surface after one year of operation and $\mathrm{R}_{\mathrm{I}} / \mathrm{R}_{\mathrm{IC}}$ was detected along this period. Nevertheless, it must be emphasised that the 
membranes did not require any chemical cleaning after more than two years of operation, even with high MLTS and temperature shocks affecting the biomass population and the derived compounds. These results revealed that reversible fouling was successfully removed from the membrane surface and that irreversible fouling was low, mainly due to applying physical cleaning mechanisms (relaxation, back-flush and shear intensity gas sparging) and operating membranes under sub-critical filtration conditions. These results suggested that operating membranes under sub-critical filtration conditions during longterm operation minimises the likelihood of membranes being irreversibly fouled.

However, it is well known that operating membranes under sub-critical rather than critical levels implies a higher total filtration area at a given $\mathbf{J}_{20}$. Nevertheless, this larger filtration area will probably increase the membrane lifespan whilst decreasing maintaining necessities. Hence, a reduction in replacement, maintenance and operating costs can be achieved.

\subsection{Short-term trials: main factors affecting membrane performance}

\subsubsection{Effect of gas sparging intensity}

Different sub-critical short-term trials were carried out at $0.17,0.23,0.33$ and 0.40 $\mathrm{Nm}^{3} \mathrm{~h}^{-1} \mathrm{~m}^{-2}$ of $\mathrm{SGD}_{\mathrm{m}}$ and MLTS of $20 \mathrm{~g} \mathrm{~L}^{-1}$. An almost stable $\mathrm{K}_{0}$ close to 1 (i.e. $\mathrm{K}_{20}(\mathrm{t}$ ) remained very close to $\left.\mathrm{K}_{20}(\mathrm{t}=0)\right)$ was achieved in all trials. Thus, low fouling rates were observed (lower than $10 \mathrm{mbar}^{\mathrm{min}}{ }^{-1}$ ). Membrane permeability recovered to the initial value of the short-term trial, indicating that no irreversible fouling component was detected. These results reveal that a $\mathrm{SGD}_{\mathrm{m}}$ of $0.17 \mathrm{Nm}^{3} \mathrm{~h}^{-1} \mathrm{~m}^{-2}$ (equal to $5 \mathrm{~cm} \mathrm{~s}^{-1}$ i.e. the minimum value supplied by the blower) was enough to completely remove the reversible fouling from the membrane surface. 


\subsubsection{Major role of gas sparging intensity when operating supra-critically}

318

319

320

321

322

Figure 3 shows the resulting $\mathrm{K}_{0}$ at different $\mathrm{SGD}_{\mathrm{m}}$ when the membranes were operated with high MLTS, and thereby at supra-critical filtration conditions. The $\mathrm{SGD}_{\mathrm{m}}$ was set to $0.23 \mathrm{Nm}^{3} \mathrm{~h}^{-1} \mathrm{~m}^{-2}$ when the MLTS level fed to the membrane tank was 28 and $31.5 \mathrm{~g} \mathrm{~L}^{-1}$, whilst the $\mathrm{SGD}_{\mathrm{m}}$ was set to $0.17 \mathrm{Nm}^{3} \mathrm{~h}^{-1} \mathrm{~m}^{-2}$ when operating at an MLTS of $30 \mathrm{~g} \mathrm{~L}^{-1}$. As it can be observed in Figure 3, even operating at similar MLTS levels, the two short-term trials carried out at MLTS of 28 and $30 \mathrm{~g} \mathrm{~L}^{-1}$ and different $\mathrm{SGD}_{\mathrm{m}}$ resulted in quite different behaviours. A sharp decrease in $\mathrm{K}_{0}$ was detected in the short-term trial conducted at the lowest $\operatorname{SGD}_{\mathrm{m}}\left(0.17 \mathrm{Nm}^{3} \mathrm{~h}^{-1} \mathrm{~m}^{-2}\right)$. In these operating conditions, a considerable increase of the reversible fouling rate was observed throughout the trial (up to $80 \mathrm{mbar}^{\mathrm{min}}{ }^{-1}$ ). In this case, the $\mathrm{SGD}_{\mathrm{m}}$ applied was not enough to fulfil the membrane scouring necessities, and the filtration process was stopped because the maximum TMP (safety value set to 0.4 bars) was reached. On the other hand, in the trial carried out at $0.23 \mathrm{Nm}^{3} \mathrm{~h}^{-1} \mathrm{~m}^{-2}$ (equal to $7 \mathrm{~cm} \mathrm{~s}^{-1}$ ) and an MLTS of $28 \mathrm{~g} \mathrm{~L}^{-1}, \mathrm{~K}_{0}$ did not reach unsustainable values (the reversible fouling rate remained at values lower than 25 mbar $\min ^{-1}$.). However, $\mathrm{K}_{0}$ decreased continuously throughout the trial as the reversible fouling was accumulated over the membrane. This accumulation could lead to a high irreversible/irrecoverable fouling propensity.

\section{It is important to highlight that the $\mathrm{SGD}_{\mathrm{m}}$ applied in these short-term trials $\left(0.23 \mathrm{Nm}^{3}\right.$} $\mathrm{h}^{-1} \mathrm{~m}^{-2}$ ) was quite low compared to the typical operating range the supplier proposed for aerobic processes (from 0.3 to $0.7 \mathrm{Nm}^{3} \mathrm{~h}^{-1} \mathrm{~m}^{-2}$ ). 
$342\left(0.23 \mathrm{Nm}^{3} \mathrm{~h}^{-1} \mathrm{~m}^{-2}\right)$ resulted in a significant decrease of $\mathrm{K}_{0}$. In the trial with an MLTS of

$343 \quad 31.5 \mathrm{~g} \mathrm{~L}^{-1}$, an increase in the membrane reversible fouling rate of up to $80 \mathrm{mbar}^{\mathrm{min}}{ }^{-1}$ was

344 observed. The maximum TMP value was reached after 140 minutes and the trial was

345 stopped. Hence, as a result of operating under critical filtration conditions, small

346 variations in the MLTS concentration affected membrane performance considerably.

347 Nevertheless, previous studies (flux-step type, see Robles et al., 2012c) showed that it is

348 theoretically possible to operate sub-critically at $10 \mathrm{LMH}$ of $\mathrm{J}_{20}$ and MLTS of $28 \mathrm{~g} \mathrm{~L}^{-1}$

349 when $\mathrm{SGD}_{\mathrm{m}}$ is about $0.25 \mathrm{Nm}^{3} \mathrm{~h}^{-1} \mathrm{~m}^{-2}$. Therefore, it is assumed that gas sparging

350 intensities around $0.3-0.5 \mathrm{Nm}^{3} \mathrm{~h}^{-1} \mathrm{~m}^{-2}$ may keep $\mathrm{K}_{0}$ at proper values when operating at

351 MLTS levels around $30-31.5 \mathrm{~g} \mathrm{~L}^{-1}$.

352

The results shown in Figure 3 suggest that when membranes are operated supracritically at low specific $\mathrm{SGD}_{\mathrm{m}}$ the duration and/or frequency of the physical cleaning stages (relaxation and back-flush) must be increased considerably. On the other hand, in order to operate the membranes sub-critically at $13.3 \mathrm{LMH}$ of $\mathrm{J}_{20}$ and MLTS levels of 23 and $28 \mathrm{~g} \mathrm{~L}^{-1}$, the theoretical $\mathrm{SGD}_{\mathrm{m}}$ required is approx. 0.23 and $0.45 \mathrm{Nm}^{3} \mathrm{~h}^{-1} \mathrm{~m}^{-2}$ (both calculated using the flux-step method), respectively. In contrast, $\mathrm{SGD}_{\mathrm{m}}$ values lower than $0.1 \mathrm{Nm}^{3} \mathrm{~h}^{-1} \mathrm{~m}^{-2}$ are theoretically needed when operating sub-critically at $13.3 \mathrm{LMH}$ of $\mathrm{J}_{20}$ and MLTS levels of $11.5 \mathrm{~g} \mathrm{~L}^{-1}$, which are quite low when compared with aerobic MBR technology operating in similar conditions.

\subsubsection{Gas sparging intensity as a key operating parameter for optimising SAnMBRs at} the industrial scale

$$
\text { The results obtained confirm the need to optimise the gas sparging intensity in all }
$$
membrane operating conditions. The gas sparging intensity poses a major challenge since 
368 it must be minimised in order to maximise energy savings. It is important to emphasise

369 that aeration energy can account for up to $50-75 \%$ of all the energy consumed by

370 aerobic MBR technology (Verrecht et al., 2010). Not only can considerable energy

371 savings be achieved but also appropriate long-term operating because the onset of

372 irreversible/irrecoverable fouling problems can be minimised.

373

374

Hence, controlling gas sparging to ensure appropriate membrane scouring is

375

376

377

378

379

380

381

382

383 mandatory in order to optimise the economic feasibility of operating HF membranes in full-scale SAnMBR systems. In this respect, several recently-published studies assess different monitoring strategies designed to save energy in aerobic MBR technology (see e.g. Huyskens et al., 2011; Ferrero et al., 2012). Nevertheless, the applicability of these control strategies for saving energy in SAnMBR technology on an industrial scale has yet to be evaluated.

\subsubsection{Effect of up-flow sludge velocity in the membrane tank}

Figure 4 illustrates how the up-flow sludge velocity in the membrane tank affects membrane performance. This operating variable is related to the sludge concentration factor resulting from the ratio between the sludge flow entering the membrane tank and the net permeate flow. For instance, Equation 6, 7 and 8 show the expected MLTS level in the membrane tank as a function of the MLTS level in the sludge fed to the membrane tank when the up-flow sludge velocity is set to $1.0,2.2$ and $2.7 \mathrm{~mm} \mathrm{~s}^{-1}$, respectively. This expected MLTS was calculated on the basis of a mass balance according to the abovementioned ratio between the sludge flow entering the membrane tank and the net permeate flow (i.e. according to the applied up-flow sludge velocity in the membrane tank). The permeate flow rate was set to a constant value of $300 \mathrm{~L} \mathrm{~h}^{-1}\left(\mathrm{~J}_{20}\right.$ of $\left.10 \mathrm{LMH}\right)$. 
394 As indicated by Equations 6 to 8, MLTS could theoretically rise to 43, 16 and 12\% when 395 the up-flow sludge velocity is set to $1.0,2.2$ and $2.7 \mathrm{~mm} \mathrm{~s}^{-1}$, respectively. Hence, the 396 MLTS in the membrane tank could reach prohibitive values when the concentration in the 397 sludge entering the membrane tank has considerably high values. For instance, when the 398 MLTS entering the membrane tank is $25 \mathrm{~g} \mathrm{~L}^{-1}$ and the up-flow sludge velocity is $2.7 \mathrm{~mm}$ $399 \mathrm{~s}^{-1}$ (the maximum studied value), the MLTS recycled to the anaerobic reactor is expected 400 to be around $28 \mathrm{~g} \mathrm{~L}^{-1}$.

401

Theoretical MLTS $S_{\text {outlet }}=1.43 \cdot$ MLTS $_{\text {Inlet }}$

(Equation 6)

403

Theoretical MLTS $S_{\text {outlet }}=1.16 \cdot$ MLTS $_{\text {Inlet }}$

(Equation 7)

404

Theoretical MLTS $S_{\text {outlet }}=1.12 \cdot$ MLTS $_{\text {Inlet }}$

(Equation 8)

405

Figure 4 shows the short-term trials carried out with MLTS of $18 \mathrm{~g} \mathrm{~L}^{-1}$ and an upflow sludge velocity of $1 \mathrm{~mm} \mathrm{~s}^{-1}$ (i.e. sub-critical conditions), and MLTS of $28 \mathrm{~g} \mathrm{~L}^{-1}$ and an up-flow sludge velocity of $1,2.2$ and $2.7 \mathrm{~mm} \mathrm{~s}^{-1}$ (i.e. critical/supra-critical conditions). Figure 4 shows that $K_{0}$ remained at values close to 1 when operating membranes subcritically. In this respect, the reversible fouling rate remained at values lower than 10 $411 \mathrm{mbar}^{-1}$. Up-flow sludge velocities of less than $1 \mathrm{~mm} \mathrm{~s}^{-1}$ when operating with MLTS 412 of $18 \mathrm{~g} \mathrm{~L}^{-1}$ resulted in critical filtration conditions (data not shown) as a result of the corresponding increase in MLTS in the membrane tank. On the other hand, this figure

414 illustrates that the up-flow sludge velocity had a significant effect on $\mathrm{K}_{0}$ when the 415 membranes were operated at high MLTS levels (around $28 \mathrm{~g} \mathrm{~L}^{-1}$, i.e. critical/supra416 critical filtration conditions). For instance, at an up-flow sludge velocity of $1 \mathrm{~mm} \mathrm{~s}^{-1}$, the 417 maximum TMP value was reached at minute 50, so the filtration process was promptly 418 stopped. In this case, a maximum reversible fouling rate of about $90 \mathrm{mbar}^{\mathrm{min}}{ }^{-1}$ was observed. On the other hand, when the up-flow sludge velocity was set to 2.7 and $2.2 \mathrm{~mm}$ 
$420 \mathrm{~s}^{-1}$ a maximum reversible fouling rate of around 10 and $20 \mathrm{mbar}^{-1} \mathrm{~min}^{-1}$ was achieved,

421 respectively. In both cases, $\mathrm{K}_{0}$ recovered to values lower than $10 \mathrm{mbar}^{\mathrm{min}}{ }^{-1}$ after back-

422 flushing. Hence, it was possible to keep the filtration process operating at appropriate

423 TMP values.

424

425

These results show that in order to keep the filtration process working properly, the

426

427

428

429

430

431

432

433

434

435

436

437

438

439

440

441

442

443

444

445 operating up-flow sludge velocity must be selected carefully depending on the operating conditions. When the membranes are operated at high MLTS levels, the up-flow sludge velocity in the membrane tank has to be high enough not only to keep MLTS at suitable levels, but also to minimise the energy consumption needed to keep $\mathbf{J}_{20}$ at sub-critical levels (e.g. required $\mathrm{SGD}_{\mathrm{m}}$ ). Nonetheless, up-flow sludge velocity must be minimised in order to maximise energy savings since pumping energy accounts for up to $15-20 \%$ of all the energy consumed by aerobic MBR technology (Verrecht et al., 2010). Hence, it is advisable for the up-flow sludge velocity to be regulated in order to optimise the economic feasibility of HF membranes in full-scale SAnMBR systems.

Another aspect that must be taken into account is whether or not the up-flow sludge is well distributed over the filtration area. A sludge flow distributed evenly across the membrane tank helps remedy any death zones and minimises the likelihood of clogging. Consequently, a minimum up-flow sludge velocity is required to ensure that the sludge is adequately distributed over the filtration area. The configuration of the membrane tank is important in this respect.

\subsubsection{Effect of back-flush frequency}


and frequency of the different physical cleaning stages (relaxation and back-flush) on membrane performance. Figure 5 shows the effect of back-flush frequency on membrane permeability with MLTS of 24, 28 and $31.5 \mathrm{~g} \mathrm{~L}^{-1}$. Two different back-flush frequencies were tested: 30 seconds of back-flush every 10 F-R basic cycles (1:10) and 30 seconds of back-flush every 30 F-R basic cycles (1:30) (Figure 5a and Figure 5b, respectively).

Figure 5 shows that at MLTS levels of less than $24 \mathrm{~g} \mathrm{~L}^{-1}$, the $\mathrm{K}_{0}$ performance was independent of the back-flush frequency, at the selected operating conditions. In these short-term trials, the reversible fouling rate remained less than $5 \mathrm{mbar}^{\mathrm{min}^{-1}}$, and no residual fouling component was observed. Hence, a complete recovery of $\mathrm{K}_{0}$ was achieved after each relaxation stage. At MLTS levels above $24 \mathrm{~g} \mathrm{~L}^{-1}$, a significant decrease in $\mathrm{K}_{0}$ was detected, making it necessary to increase the back-flush frequency from 1:30 to 1:10 in order to keep the filtration process working below the TMP safety value mentioned earlier. In this respect, when the back-flush frequency was set to 1:30, the maximum reversible fouling rate reached was around 25 and $80 \mathrm{mbar}^{-1} \mathrm{~min}^{-1}$, at MLTS levels of 28 and $31.5 \mathrm{~g} \mathrm{~L}^{-1}$, respectively. On the other hand, when the back-flush frequency was increased to $1: 10$, the maximum reversible fouling rate at an MLTS level of $28 \mathrm{~g} \mathrm{~L}^{-1}$ decreased to values around $20 \mathrm{mbar} \mathrm{min}^{-1}$. However, this higher back-flush frequency had no noticeable effect on membrane performance when the MLTS level was $31.5 \mathrm{~g} \mathrm{~L}^{-1}$, i.e. $\mathrm{K}_{0}$ quickly returned to its previous values after back-flushing.

Hence, these results showed that values of MLTS above $30 \mathrm{~g} \mathrm{~L}^{-1}$ are not advisable since increasing the back-flush frequency from 1:30 to 1:10 did not improve the membrane performance. However, at MLTS levels lower than $28 \mathrm{~g} \mathrm{~L}^{-1}$, it was possible to improve membrane performance considerably without significantly increasing the backflush frequency. 
474 the process not only because of the pumping cost but also due to the resulting decrease in 475 the net $J_{20}$. Hence, it is essential to control the back-flush frequency to ensure that the membrane is physically cleaned correctly and thereby maximise the $\mathbf{J}_{20}$ at minimum 477 operating costs.

\subsubsection{Effect of relaxation stage duration}

480

Different sub-critical short-term trials were carried out to assess how the duration of the relaxation stage affects membrane performance. Relaxation stages of 50 and 30 seconds were tested when operating at MLTS of $25 \mathrm{~g} \mathrm{~L}^{-1}$ and sub-critical filtration conditions, and at MLTS of $28 \mathrm{~g} \mathrm{~L}^{-1}$ and supra-critical filtration conditions. An almost complete recovery of $\mathrm{K}_{0}$ was achieved when the MLTS level was $25 \mathrm{~g} \mathrm{~L}^{-1}$. Hence, it was observed that membrane performance was not critically affected by relaxation stages of between 30 and 50 seconds at the selected operating conditions when operating at MLTS levels below $25 \mathrm{~g} \mathrm{~L}^{-1}$. In this case, reversible fouling rates lower than $5 \mathrm{mbar}^{\mathrm{min}^{-1}}$ were achieved. On the other hand decreasing the relaxation stage duration from 50 to 30 seconds at MLTS levels of $28 \mathrm{~g} \mathrm{~L}^{-1}$ slightly affected membrane performance, i.e. a slight increase in the reversible fouling component that accumulated on the membrane surface was observed (see Figure 6). In this case, the reversible fouling rate reached values of around $10 \mathrm{mbar}^{\mathrm{min}}{ }^{-1}$. However, the TMP recovered to values lower than 0.1 bars after 494 back-flushing. 

from 1:30 to $1: 10$ did not improve membrane performance. It was not possible to test

accumulation of reversible fouling components upon over the membrane surface could lead to an increased likelihood of irreversible fouling. For that reason, reducing the relaxation stage from 50 to 30 seconds when membranes are operated at MLTS levels higher than $25 \mathrm{~g} \mathrm{~L}^{-1}$ is not recommendable, if the other operating conditions are kept constant (250-second filtration stage, 30 seconds of back-flush every 10 F-R cycles, 10 LMH of $\mathrm{J}_{20}$, and $\mathrm{SGD}_{\mathrm{m}}$ at $0.23 \mathrm{Nm}^{3} \mathrm{~h}^{-1} \mathrm{~m}^{-2}$ ).

Relaxation stage duration affects the economic feasibility of the process because of the resulting decrease in the net $\mathrm{J}_{20}$. Hence, it is advisable to control the length of the relaxation stage in order to ensure that the membrane is correctly cleaned physically and thereby minimise the decrease in the net transmembrane flux whilst minimising the operating cost per unit of treated water (e.g. reducing the specific gas demand per volume of permeate).

\subsubsection{Effect of filtration stage duration}

Figure 7 shows an example of the short-term trials carried out in order to assess the effect of filtration stage duration on membrane performance. Duration was set to 250, 350 and 450 seconds. In this case, the MLTS level in the sludge fed to the membrane tank was 23 and $31.5 \mathrm{~g} \mathrm{~L}^{-1}$ and the back-flush frequency was set to 30 seconds of backflushing every 10 F-R basic cycles (Figure 7a), and 30 seconds of back-flushing every 30 F-R basic cycles (Figure 7b).

\section{Figure 7 shows that with MLTS of $31.5 \mathrm{~g} \mathrm{~L}^{-1}$, increasing the back-flush frequency} filtration lasting more than 250 seconds because the maximum TMP value was reached in 
both 250 -second trials.

525

In the short-term trials carried out with MLTS of $23 \mathrm{~g} \mathrm{~L}^{-1}$, an increase in the filtration

527

528

529

530

531

532

533

534

535

536

537

538

539

540

541

542

543

544

545

546

547

548

549

stage duration from 250 to 450 seconds resulted in the incomplete removal of the reversible fouling component from the membrane surface. Despite no high reversible fouling rates having been reached, a slight and continuous decrease of $\mathrm{K}_{0}$ over time was observed when the filtration stage duration was set to 450 seconds: an effect that was slightly accentuated when the back-flush frequency was reduced from 1:10 to 1:30.

Increasing the duration of the filtration stage causes an increase in net $\mathbf{J}_{20}$. However, as observed in this trial, it is essential to strike a balance between maximising net $\mathbf{J}_{20}$ and minimising maintenance and operating costs.

\subsubsection{Overall effect of MLTS and sustainable operating MLTS level}

$$
\text { On the basis of the results shown in this study, we established a critical value for }
$$
long-term membrane operating of around $20-25 \mathrm{~g} \mathrm{~L}^{-1}$. Since several operating variables considerably affect the appearance of reversible fouling at short-term, this maximum operating MLTS was established for the following scenario: 300-second basic F-R cycles (250 s filtration and 30-50 s relaxation) with 30 seconds of back-flush every 10 cycles; $\mathbf{J}_{20}$ of about $10 \mathrm{LMH}$; $\mathrm{SGD}_{\mathrm{m}}$ of $0.23 \mathrm{Nm}^{3} \mathrm{~h}^{-1} \mathrm{~m}^{-2}$; and up-flow sludge velocity of $2.7 \mathrm{~mm} \mathrm{~s}^{-1}$. For this specific scenario, increasing the filtration stage duration over $250 \mathrm{~s}$ will lead to a progressively reduction in $\mathrm{K}_{0}$ over time, being this effect greater when the back-flush frequency is decreased to 1 back-flush every 30 F-R cycles (see Figure 7). On the other hand, back-flushing can be decreased from a frequency of 1 back-flush every 10 F-R cycles to 1 back-flush every 30 F-R cycles when membranes are operated at MLTS levels 
lower that $24 \mathrm{~g} \mathrm{~L}^{-1}$, whilst the same increase considerably affects $\mathrm{K}_{0}$ when the MLTS is

551 around $28 \mathrm{~g} \mathrm{~L}^{-1}$ (see Figure 5). As regards gas sparging intensity, an $\mathrm{SGD}_{\mathrm{m}}$ of around $5520.17-0.23 \mathrm{Nm}^{3} \mathrm{~h}^{-1} \mathrm{~m}^{-2}$ allows maintaining proper long-term operation when the MLTS 553 entering the membrane tank is around $20 \mathrm{~g} \mathrm{~L}^{-1}$, whilst this value is not enough to properly 554 operate at MLTS levels around $28 \mathrm{~g} \mathrm{~L}^{-1}$ (see Figure 3). Finally, reducing the up-flow 555 sludge velocity from 2.7 to $2.2 \mathrm{~mm} \mathrm{~s}^{-1}$ may lead to a considerable decrease in $\mathrm{K}_{0}$, due to a 556 significant increase in the MLTS level when its concentration entering the membrane 557 tank is around $28 \mathrm{~g} \mathrm{~L}^{-1}$ (see Figure 4).

\section{8}

559

Functioning with similar operating modes may allow reducing the offset of 560 irreversible/irrecoverable fouling at long-term operation since the accumulation of 561 reversible fouling component over the membrane surface can be minimised.

\subsection{Overall membrane operation compared to full-scale aerobic MBR plant.}

On the basis of the long-term results obtained in this work, MLTS levels above $25 \mathrm{~g}$

$\mathrm{L}^{-1}$ are not recommended for commercial HF membranes because $\mathrm{J}_{\mathrm{C}}$ drops to less than 10

567 LMH, making the filtration process unnecessarily expensive. On the basis of the short-

568 term results, two opposite design strategies could be applied depending on the operating

569 regime adopted. If the design strategy is based on sub-critical operating, the installed

570 filtration area must be increased - which increases the initial investment. On the other

571 hand, if the design strategy selected is based on supra-critical operating, then high back-

572 flush frequencies and/or unsustainable $\mathrm{SGD}_{\mathrm{m}}$ are required - which increases operating

573 and maintenance/replacement costs. This may result in low process efficiency per unit of

574 treated water (i.e. a decrease in net $\mathbf{J}_{20}$ ) or high energy consumption, respectively. 
577 working at sub-critical filtration conditions is an adequate operating strategy for

578 SAnMBR technology because no considerable irreversible/irrecoverable fouling

579 component was detected after operating for almost two years. Indeed, membranes did not

580 required chemical cleaning. Nevertheless, an exhaustive economic analysis is needed to

581 accurately demonstrate the feasibility of working at sub-critical or critical/supra-critical

582 levels in an specific scenario. However, in order to shed more light upon the economic

583 feasibility of SAnMBR technology for treating urban wastewater, the long-term operating

584 strategy proposed in our study is compared in tables 2 and 3 with some available data 585 related to full-scale aerobic MBR operations.

586

587

\subsubsection{Average operating values for transmembrane flux, membrane permeability and} specific gas demand

589

590

Table 2 shows a summary of data for full-scale aerobic plants treating both urban and

591 industrial wastewater with submerged MBR (extracted from Judd and Judd, 2011) and the average values obtained throughout the long-term operation of our study.

Using FS membranes in urban wastewater treatment enables higher transmembrane 595 fluxes (19.4 LMH) and membrane permeability (261 LMH bar ${ }^{-1}$ ) in comparison with the results obtained in our work: transmembrane fluxes of around $11 \mathrm{LMH}$, resulting in membrane permeability of $135 \mathrm{LMH} \mathrm{bar}^{-1}$ in average. However, higher $\mathrm{SGD}_{\mathrm{m}}$ and higher 598 specific gas demand with respect to permeate volume $\left(\mathrm{SGD}_{\mathrm{P}}\right)$ are commonly required in 599 FS technology (see Table 2). It is well known that HF technology allows some degree of lateral movement which enables greater cake layer detachment at lower gas sparging intensities than in FS technology. On the other hand, when using FS membranes to treat 
industrial wastewater, commonly operating at high MLTS levels, the transmembrane

603 fluxes and membrane permeability are similar to those obtained in our study. However, 604 considerably higher $\mathrm{SGD}_{\mathrm{m}}$ and $\mathrm{SGD}_{\mathrm{P}}$ are reported when using FS membranes.

605

As regards HF technology, the results from full-scale aerobic operation are similar to

607 the results obtained in our study. Both aerobic and anaerobic operation result in

608 reasonably adequate transmembrane fluxes and membrane permeability by applying low

609 air/gas demands. In this respect, even though the resulting $\mathbf{J}_{20}$ was lower in the case of

610 anaerobic HF membranes (around $11 \mathrm{LMH}$ vs. approx. $17 \mathrm{LMH}$ ), higher $\mathrm{K}_{20}$ levels were

611 obtained (around $135 \mathrm{LMH} \mathrm{bar}^{-1}$ vs. approx. $75 \mathrm{LMH} \mathrm{bar}^{-1}$ ) whilst applying similar

$612 \mathrm{SGD}_{\mathrm{m}}$ (around $0.25 \mathrm{Nm}^{3} \mathrm{~h}^{-1} \mathrm{~m}^{-2}$ ) in both anaerobic and aerobic HF. Moreover, SGD

613 remained in a similar range (from approx. 15.5 to approx. 20.5) in both cases. Some

614 studies suggested that the cake layer formed with aerobic and anaerobic sludge might

615 have different removability (see e.g. Meng et al., 2009). Nevertheless, based on

616 comparable results for the aerobic and anaerobic operation of HF membranes, it can be

617 assumed in this study that differences between anaerobic and aerobic sludge properties

618 (i.e. particle size distribution, EPS, SMP and biomass concentration, etc.) did not

619 critically determine the removability of the cake layer from the membrane surface. In this

620 respect, HF technology is a promising, competitive technology for the anaerobic

621 treatment of urban wastewater.

622

\subsubsection{Physical and chemical cleaning requirements}

624

625

A summary of the physical cleaning protocols for full-scale aerobic MBRs treating urban wastewater (extracted from Judd and Judd, 2011) and the average values applied throughout the long-term operation of our study are shown in table 3. Full-scale results 
628 from aerobic MBR technology reveal a relaxation downtime of around $10 \%$ of the 629 operating time in both FS and HF configurations. This value is significantly lower than 630 the resulting relaxation downtime obtained in our study (around 16.7\% of the operating time). However, the relaxation stage duration applied in our work can be considered as a quite conservative value - selected in order to avoid possible problems when operating at large MLTS concentrations - since the results from the short-term trials showed that it is

634 possible to reduce this parameter to a value of 30 seconds with a minimum impact on membrane performance when operating at MLTS levels below $25 \mathrm{~g} \mathrm{~L}^{-1}$. This decrease in the duration of the relaxation stage results in a downtime of around $10 \%$ of operating time, which is similar to the average downtime shown in table 3 for full-scale aerobic MBRs. On the other hand, a back-flush downtime of around $6-9 \%$ of operating time was reported by Judd and Judd (2011) in the aerobic treatment of urban wastewater in full-scale MBRs. In this respect, only an additional downtime of around $1 \%$ of the operating period was obtained in our study (carried out with a back-flush frequency of 0.5 min every 10 F-R cycles). This gives a total average downtime for physical cleaning of $17.7 \%$ of operating time throughout the long-term operation of HF membranes shown in our study (instead of an average downtime of around $16-19 \%$ when using HF technology to treat urban wastewater aerobically). Moreover, it is important to emphasise that the membranes in our study did not require chemical cleaning after operating for more than two years - despite operating at high MLTS levels and with temperature shocks that affected mixed sludge properties - which is a considerably longer than the periods usually employed in aerobic MBR technology.

Hence, the results of our study predict that HF membranes will result in a sustainable approach for SAnMBR technology compared to the full-scale results reported for aerobic MBR technology. 


\section{Conclusions}

656

657

The membrane performance demonstrated that HF-SAnMBR may be a promising technology for urban wastewater treatment since low maintenance and operating costs related to membrane separation process can be achieved. According to the results, gas sparging intensity and back-flush frequency are the physical variables that affect membrane performance most. In our study, low gas sparging intensities (around 0.23 $\mathrm{Nm}^{3} \mathrm{~h}^{-1} \mathrm{~m}^{-2}$ ) and low BF frequencies (30 seconds of BF every 10 basic F-R cycle) were enough to operate membranes sub-critically even at high levels of MLTS (up to $25 \mathrm{~g} \mathrm{~L}^{-1}$ ).

On the other hand, operating at critical filtration conditions involves significant physical cleaning (gas sparging intensity and BF frequency) to ensure that membranes operate correctly. The results of our study show that establishing a suitable physical cleaning schedule (relaxation, back-flush and gas sparging intensity) enhances the removal of the reversible fouling component accumulated on the membrane surface, and thus minimises the irreversible fouling propensity. After more than two years of sub-critical operation (transmembrane flux between 9 and 13.3 LMH at gas sparging intensities of around 0.23 $\mathrm{Nm}^{3} \mathrm{~h}^{-1} \mathrm{~m}^{-2}$ and MLTS levels in the mixed liquor entering the membrane tank of around

67210 to $30 \mathrm{~g} \mathrm{~L}^{-1}$ ) no significant irreversible/irrecoverable fouling problems were detected 673 (membrane permeability remained above $100 \mathrm{LMH} \mathrm{bar}^{-1}$ and total filtration resistance 674 remained below $10^{13} \mathrm{~m}^{-1}$ ), thus no chemical cleaning was conducted. Membrane performance was similar to the aerobic HF membranes operated in full-scale MBR plants.

676 On the basis of the different experiments carried out, different control strategies will be 677 developed with a view to optimising membrane performance in both sub-critical and critical/supra-critical operating. Nevertheless, an exhaustive economic analysis is needed to make the best choice between the two different operating regimes in a specific 


\section{Acknowledgements}

683

684

This research work has been supported by the Spanish Research Foundation (CICYT

685

Projects CTM2008-06809-C02-01 and CTM2008-06809-C02-02, and MICINN FPI grant

BES-2009-023712) and Generalitat Valenciana (Projects GVA-ACOMP2010/130 and

687 GVA-ACOMP2011/182), which are gratefully acknowledged.

688

\section{References}

690

691

APHA, 2005. Standard methods for the Examination of Water and Wastewater, $21^{\text {st }}$ edition. American

692 Public Health Association/American Water Works Association/Water Environmental Federation,

693 Washington DC, USA.

694 Bachin, P., Aimar, P., Sanchez, V., 1995. Model for colloidal fouling of membranes. AIChE Journal 41 (2), $695 \quad 368-377$.

696 Cote, P., Alam, Z., Penny, J., 2012. Hollow fibre membrane life in membrane bioreactors (MBR).

697 Desalination $288(1), 145-151$.

698 Di Bella, G., Durante, F., Torregrossa, M., Viviani G., 2010. Start-up with or without inoculum? Analysis 699 of an SMBR pilot plant. Desalination 260 (1-3), 79 - 90.

700 Drews, A., 2010a. Membrane fouling in membrane bioreactors - Characterization, contradictions, causes 701 and cures. Journal of Membrane Science 253 (1-2), 1 - 28.

702 Drews, A., Prieske, H., Meyer, E.L., Senger, G., Kraume, M., 2010b. Advantageous and detrimental effects 703 of air sparging in membrane filtration: Bubble movement, exerted shear and particle classification.

704 Desalination $250(3), 1083-1086$.

705 Ferrero, G., Rodriguez-Roda, I., Comas, J., 2012. Automatic control systems for submerged membrane 706 bioreactors: A state-of-the-art review. Water Research, doi:10.1016/j.watres.2012.03.055.

707 Field, R.W., Wu, D., Howell, J.A., Gupta, B.B., 1995. Critical flux concept for microfiltration fouling. 708 Journal of Membrane Science 100 (3), 259 - 272. 
710 Seco, A., 2011 Experimental study of the anaerobic urban wastewater treatment in a submerged hollow-

711 fibre membrane bioreactor at pilot scale. Bioresource Technology 102 (19), $8799-8806$.

712 Guglielmi, G., Saroj, D. P., Chiarani, D., Andreottola, G., 2007. Sub-critical fouling in a membrane

713 bioreactor for municipal wastewater treatment: Experimental investigation and mathematical modeling.

$714 \quad$ Water Research 41 (17), 3903 - 3914.

715 Huang, Z., Ong, S.L., Ng, H.Y., 2008. Feasibility of submerged anaerobic membrane bioreactor (SAMBR)

716 for treatment of low-strength wastewater. Water Science and Technology 58 (10), $1925-1931$.

717

Huisjes, E.H., Colombel, K., Lesjean, B., 2009. The European MBR market: Specificities and future trends. Proceedings of the Final MBR-Network Workshop. Berlin, 31 March - 1 April 2009. Germany

Huyskens, C., Brauns, E., Van Hoof, E., Diels, L., De Wever, H., 2011. Validation of a supervisory control system for energy savings in membrane bioreactors. Water Research 45 (3), $1443-1453$.

Jeison, D., van Lier, J.B., 2007. Cake formation and consolidation: Main factors governing the applicable and Purification Technology 56 (1), $71-78$.

724

Judd, S., 2008. The status of membrane bioreactor technology, Trends in Biotechnology 26 (2), $109-116$.

725

Judd, S., Judd, C., 2011. The MBR Book: Principles and Applications of Membrane Bioreactors in Water and Wastewater Treatment, Second Edition, ELVESIER.

727

Lesjean, B., Huisjes, E.H., 2007. Survey of European MBR market, trends and perspectives. Proceedings of the IWA 4th International Membrane Technologies Conference, 15 - 17 May 2007, Harrogate, UK.

Lew, B., Tarre, S., Beliavski, M., Dosoretz, C., Green, M., 2009. Anaerobic membrane bioreactor (AnMBR) for domestic wastewater treatment. Desalination $243(1-3), 251-257$.

Liao, B.Q., Kraemer, J.T., and Bagley, D.M., 2006. Anaerobic membrane bioreactors: Applications and research directions. Critical Reviews in Environmental Science and Technology 36 (6), 489 - 530. properties and their effects on membrane fouling in submerged anaerobic membrane bioreactors (SAnMBRs). Water Research 43 (15), 3827 - 3837. affecting sludge cake formation in a submerged anaerobic membrane bioreactor. Journal of Membrane Science 361 (1-2), $126-134$. 

bioreactors (MBRs): Membrane fouling and membrane material. Water Research 43 (6), 1489 - 1512.

Patsios, S.I., Karabelas, A.J., 2011. An investigation of the long-term filtration performance of a membrane bioreactor (MBR): The role of specific organic fractions. Journal of Membrane Science 253 (1-2), 102 115.

Robles, A., Ruano, M.V., García-Usach, F., Ferrer, J., 2012a. Sub-critical filtration conditions of commercial hollow-fibre membranes in a submerged anaerobic MBR (HF-SAnMBR) system: The effect of gas sparging intensity. Bioresource Technology 114, $247-254$.

Robles, A., Ruano, M.V., Ribes, J., Ferrer, J., 2012b. Performance of industrial hollow-fibre membranes in a submerged anaerobic MBR (HF-SAnMBR) system under mesophilic and psychrophilic conditions. Submitted to Separation and Purification Technology.

Robles, A., Ruano, M.V., Ribes, J., Ferrer, J., 2012c. Sub-critical long-term operation of industrial scale hollow-fibre membranes in a submerged anaerobic MBR (HF-SAnMBR) system. Separation and Purification Technology 100, $88-96$.

Rosenberger, S., Laabs, C., Lesjean, B., Gnirss, R., Amy, G., Jekel, M., Schrotter J.C., 2006. Impact of colloidal and soluble organic material on membrane performance in membrane bioreactors for municipal wastewater treatment. Water Research 40 (4), 710 - 720.

Sweity, A., Ying, W., Belfer, S., Oron, G., Herzberg, M., 2011. pH effects on the adherence and fouling propensity of extracellular polymeric substances in a membrane bioreactor. Journal of Membrane Science $378(1-2), 186-193$.

van der Marel, P., Zwijnenburg, A., Kemperman, A., Wessling, M., Temmink, H., van der Meer, W., 2009. An improved flux-step method to determinate the critical flux and the critical flux for irreversibility in a membrane bioreactor. Journal of Membrane Science 332 (1-2), 24 - 29.

Verrecht, B., Maere, T., Nopens, I., Brepols, C., Judd S., 2010. The cost of a large-scale hollow fibre MBR. Water Research 44 (18), $5274-5283$.

WRC, 1992. Simple titration procedures to determine $\mathrm{H}_{2} \mathrm{CO}^{*} *$ alkalinity and short-chain fatty acids in aqueous solutions containing known concentrations of ammonium, phosphate and sulphide weak acid/bases, Report No. TT 57/92, Water Research Commission, University of Cape Town, Pretoria, 


\section{Figure and table captions}

772

773

774

775

776

777

778

779

780

781

782

783

784

785

786

787

788

789

790

791

792

793

794

795

796

797

798

799

800

Table 1. Short-term trials operating conditions (Nomenclature: MLTS: mixed liquor total solid; $\mathbf{S G D}_{\mathbf{m}}$ : specific gas demand per membrane area; BF: back-flush; F-R: filtration-relaxation)

Table 2. Summary of full-scale plant data for urban wastewater treatment: Average data for submerged MBRs (adapted from Judd and Judd (2011)). Nomenclature: FS: Flat-sheet; HF: hollow-fibre; WW: wastewater; J: transmembrane flux; K: membrane permeability; $\mathbf{S}(\mathbf{A} / \mathbf{G}) \mathbf{D}_{\mathbf{m}}$ : specific air/gas demand per membrane area; $\mathbf{S}(\mathbf{A} / \mathbf{G}) \mathbf{D}_{\mathbf{P}}$ : specific air/gas demand per permeate volume.

Table 3. Summary of full-scale urban physical cleaning protocols. Average data on submerged MBRs (adapted from Judd and Judd (2011)). Nomenclature: FS: Flat-sheet; HF: hollow-fibre; WW: wastewater; F: Filtration stage duration; R: Relaxation stage duration; BF: Back-flush stage duration.

Figure 1. Flow diagram of the pilot plant. Nomenclature: RF: rotofilter; ET: equalization tank; AnR: anaerobic reactor; MT: membrane tanks; DV: degasification vessel; CIP: clean-in-place; P: pump; and B: blower.

Figure 2. Long-term operation: evolution of (a) $\mathrm{K}_{20}$ and MLTS; and (b) $\mathrm{R}_{\mathrm{T}}$ and MLTS. Experimental periods: (i) $\mathrm{J}_{20}$ of $13.3 \mathrm{LMH}$ and temperature of $33{ }^{\circ} \mathrm{C}$; (ii) $\mathrm{J}_{20}=10 \mathrm{LMH}$ and $\mathrm{T}=33^{\circ} \mathrm{C}$; (iii) $\mathrm{J}_{20}=12 \mathrm{LMH}$ and $\mathrm{T}=25^{\circ} \mathrm{C}$; (iv) $\mathrm{J}_{20}=13.3 \mathrm{LMH}$ and $\mathrm{T}=20^{\circ} \mathrm{C}$; and (v) $\mathrm{J}_{20}=11 \mathrm{LMH}$ and ambient temperature (spring and summer, from about 20 to $30^{\circ} \mathrm{C}$ ); and (vi) $\mathrm{J}_{20}=9 \mathrm{LMH}$ and ambient temperature (autumn and winter, from about 30 to $15^{\circ} \mathrm{C}$ ).

Figure 3. Short-term trial 1: Effect of gas sparging intensity on membrane permeability at MLTS level of 28, 30 and $31.5 \mathrm{~g} \mathrm{~L}^{-1}$. Nomenclature: MLTS: mixed liquor total solids; $\mathbf{K}_{\mathbf{0}}$ : unit-normalised membrane permeability; BF: back-flush.

Figure 4. Short-term trial 2: Effect of up-flow sludge velocity on membrane permeability at MLTS levels of 18 and $28 \mathrm{~g} \mathrm{~L}^{-1}$, and up-flow sludge velocity of 1.0, 2.2, and $2.7 \mathrm{~mm} \mathrm{~s}^{-1}$. Nomenclature: MLTS: mixed liquor total solids; TS: total solids; $\mathbf{K}_{\mathbf{0}}$ : unit-normalised membrane permeability; BF: back-flush.

Figure 5. Short-term trial 3: Effect of back-flush frequency on membrane permeability at MLTS of 24, 28 and $31.5 \mathrm{~g} \mathrm{~L}^{-1}$ and (a) 30 seconds of back-flush every $10 \mathrm{~F}-\mathrm{R}$ cycles; and (b) 30 seconds of back-flush every 30 F-R cycles. Nomenclature: $\mathbf{K}_{\mathbf{0}}$ : unit-normalised membrane permeability; BF: back-flush.

Figure 6. Short-term trial 4: Effect of relaxation stage duration on membrane permeability at MLTS level 
801 of $28 \mathrm{~g} \mathrm{~L}^{-1}$. Nomenclature: $\mathbf{K}_{\mathbf{0}}$ : unit-normalised membrane permeability; BF: back-flush.

802 Figure 7. Short-term trial 5: Effect of filtration stage duration on membrane permeability at (a) MLTS

803 levels of 23 and $31.5 \mathrm{~g} \mathrm{~L}^{-1}$ and back-flush frequency of 1 back-flush every $10 \mathrm{~F}-\mathrm{R}$ cycles; and (b) MLTS

804 levels of 23 and $31.5 \mathrm{~g} \mathrm{~L}^{-1}$ and back-flush frequency of 1 back-flush every $30 \mathrm{~F}-\mathrm{R}$ cycles. Nomenclature:

$805 \mathbf{K}_{\mathbf{0}}$ : unit-normalised membrane permeability; BF: back-flush. 
Table 1. Short-term trials operating conditions (Nomenclature: MLTS: mixed liquor total solid; $\mathbf{S G D}_{\mathbf{m}}$ : specific gas demand per membrane area; BF: back-flush; F-R: filtration-relaxation)

\begin{tabular}{|c|c|c|c|c|c|}
\hline \multirow[b]{2}{*}{ Trial } & \multirow{2}{*}{$\begin{array}{l}\text { Variable } \\
\text { studied }\end{array}$} & \multicolumn{2}{|c|}{ Sub-critical conditions } & \multicolumn{2}{|c|}{ Supra-critical/Critical conditions } \\
\hline & & Value & $\begin{array}{l}\text { MLTS } \\
\left(\mathrm{g} \mathrm{L}^{-1}\right) \\
\end{array}$ & Value & $\begin{array}{l}\text { MLTS } \\
\left(g^{-1}\right)^{-1} \\
\end{array}$ \\
\hline \multirow{2}{*}{1} & \multirow{2}{*}{$\begin{array}{l}\mathrm{SGD}_{\mathrm{m}} \\
\left(\mathrm{Nm}^{3} \mathrm{~h}^{-1} \mathrm{~m}^{-2}\right)\end{array}$} & \multirow{2}{*}{$\begin{array}{c}0.17,0.23,0.3 \\
0.4\end{array}$} & \multirow{2}{*}{20} & 0.17 & 30 \\
\hline & & & & 0.23 & $28,31.5$ \\
\hline 2 & $\begin{array}{l}\text { Up-flow } \\
\text { sludge } \\
\text { velocity } \\
\left(\mathrm{mm} \mathrm{s}^{-1}\right) \\
\end{array}$ & 1.3 & 18 & $1.0,2.2,2.7$ & 28 \\
\hline 3 & $\begin{array}{l}\text { BF frequency } \\
(\mathrm{BF}: \mathrm{F}-\mathrm{R})\end{array}$ & $1: 10,1: 30$ & 24 & $1: 10,1: 30$ & $28,31.5$ \\
\hline 4 & $\begin{array}{l}\text { Relaxation } \\
\text { stage duration } \\
\text { (seconds) }\end{array}$ & 30,50 & 25 & 30,50 & 28 \\
\hline \multirow{2}{*}{5} & \multirow{2}{*}{$\begin{array}{l}\text { Filtration } \\
\text { stage duration } \\
\text { (seconds) }\end{array}$} & $\begin{array}{c}250,350,450 \\
(1 \mathrm{BF}: 10 \mathrm{~F}-\mathrm{R})\end{array}$ & \multirow{2}{*}{23} & $\begin{array}{c}250 \\
(1 \mathrm{BF}: 10 \mathrm{~F}-\mathrm{R})\end{array}$ & \multirow{2}{*}{31.5} \\
\hline & & $\begin{array}{l}250,350,450 \\
(1 \mathrm{BF}: 30 \mathrm{~F}-\mathrm{R})\end{array}$ & & $\begin{array}{c}250 \\
(1 \mathrm{BF}: 30 \mathrm{~F}-\mathrm{R})\end{array}$ & \\
\hline
\end{tabular}


Table 2. Summary of full-scale plant data for urban wastewater treatment: Average data for submerged MBRs (adapted from Judd and Judd (2011)). Nomenclature: FS: Flat-sheet; HF: hollow-fibre; WW: wastewater; J: transmembrane flux; K: membrane permeability; $\mathbf{S}(\mathbf{A} / \mathbf{G}) \mathbf{D}_{\mathbf{m}}$ : specific air/gas demand per membrane area; $\mathbf{S}(\mathbf{A} / \mathbf{G}) \mathbf{D}_{\mathbf{P}}$ : specific air/gas demand per permeate volume.

\begin{tabular}{llcccc}
\hline Technology & Treatment & $\mathbf{J}$ & $\mathbf{K}$ & $\mathbf{S}(\mathbf{A} / \mathbf{G}) \mathbf{D}_{\mathbf{m}}$ & $\mathbf{S}(\mathbf{A} / \mathbf{G}) \mathbf{D}_{\mathbf{P}}$ \\
& & $(\mathbf{L M H})$ & $\left(\mathbf{L M H} \mathbf{~ b a r}^{-\mathbf{1}}\right)$ & $\left.\mathbf{( N m}^{\mathbf{3}} \mathbf{h}^{\mathbf{- 1}} \mathbf{~ m}^{\mathbf{- 2}}\right)$ & \\
\hline FS & Aerobic; Urban WW & 19.4 & 261 & 0.57 & 27.5 \\
\hline FS & Aerobic; Industrial WW & 13.4 & -- & 0.80 & 91.9 \\
\hline HF & Aerobic; Urban WW & 19.5 & 104 & 0.30 & 15.4 \\
\hline HF & Aerobic; Industrial WW & 15.4 & 47 & 0.23 & 16.5 \\
\hline \multirow{2}{*}{ This study (HF) } & Anaerobic; & 11.1 & 135 & 0.23 & 20.7 \\
\hline
\end{tabular}


Table 3. Summary of full-scale urban physical cleaning protocols. Average data on submerged MBRs (adapted from Judd and Judd (2011)). Nomenclature: FS: Flat-sheet; HF: hollow-fibre; WW: wastewater; F: Filtration stage duration; R: Relaxation stage duration; BF: Back-flush stage duration.

\begin{tabular}{llccc}
\hline Technology & Treatment & $\mathbf{F}$ & $\mathbf{R}$ & BF \\
& & $(\mathbf{m i n})$ & $(\mathbf{m i n})$ & (min) \\
\hline FS & Aerobic; Urban WW & 22.0 & 2.2 & -- \\
\hline HF & Aerobic; Urban WW & 10.0 & 1.0 & 0.43 \\
\hline This study (HF) & Anaerobic; Urban WW & 4.2 & 0.8 & 0.50 \\
\hline
\end{tabular}




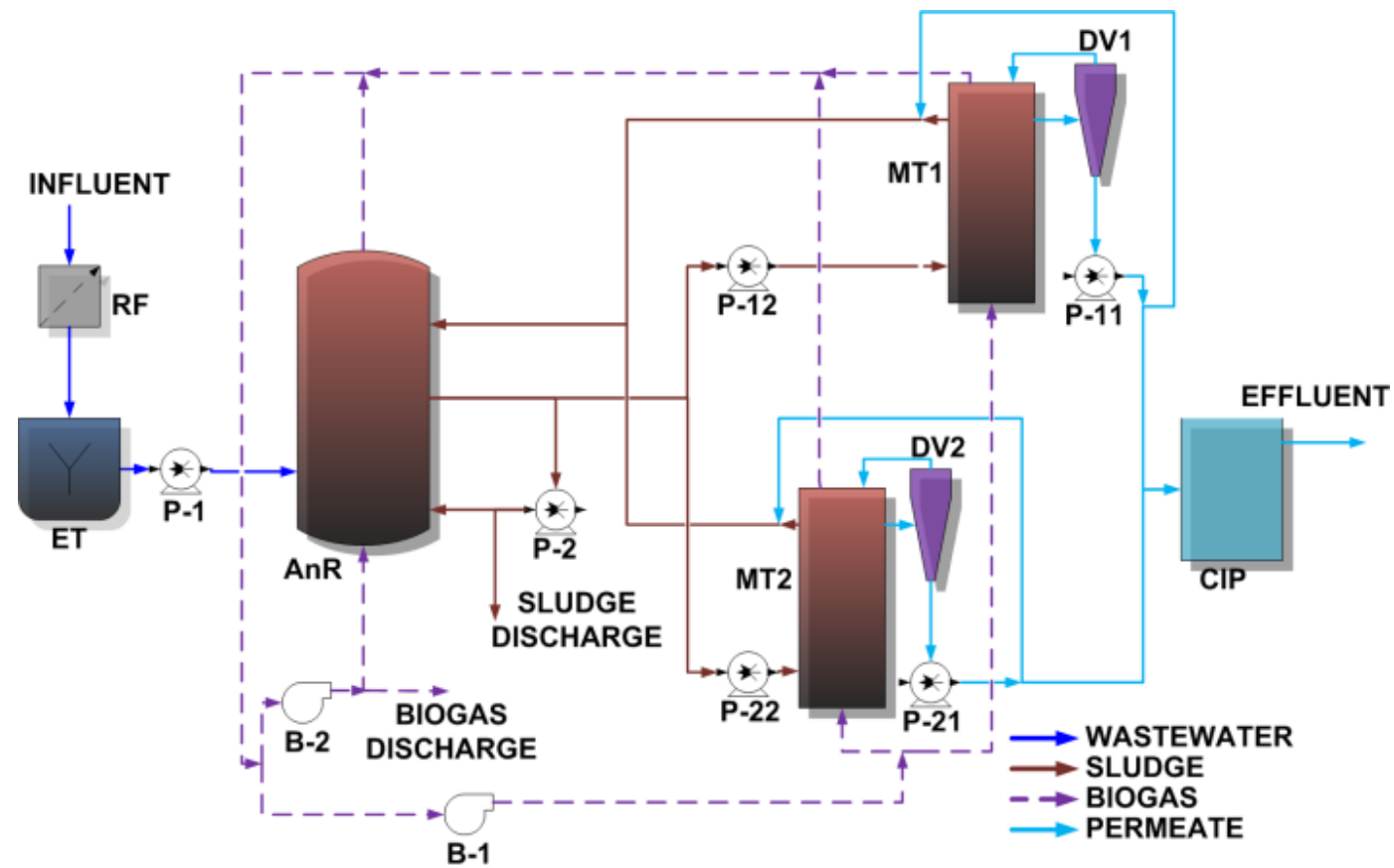

Figure 1. Flow diagram of the pilot plant. Nomenclature: RF: rotofilter; ET: equalization tank; AnR:

anaerobic reactor; MT: membrane tanks; DV: degasification vessel; CIP: clean-in-place; P: pump; and B: blower. 


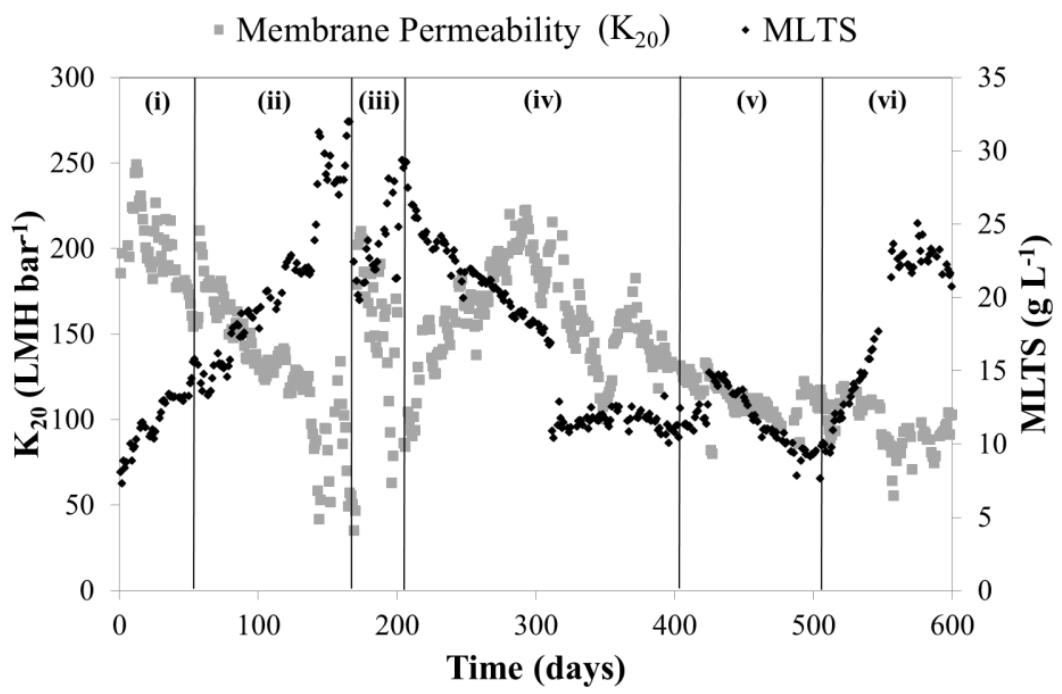

(a)

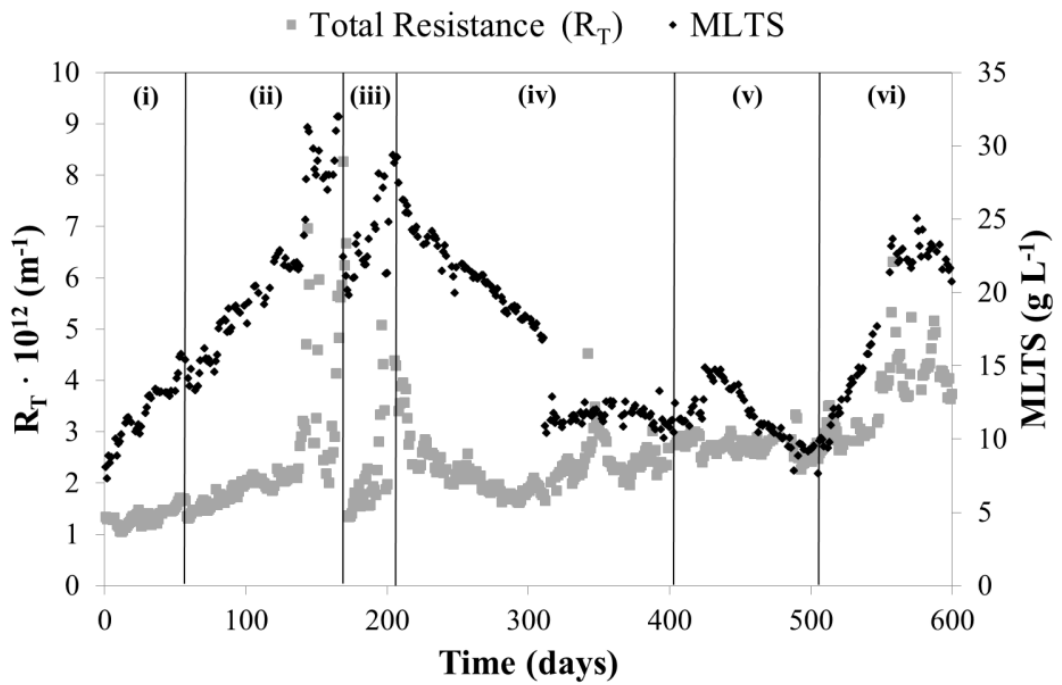

(b)

Figure 2. Long-term operation: evolution of (a) $\mathrm{K}_{20}$ and MLTS; and (b) $\mathrm{R}_{\mathrm{T}}$ and MLTS. Experimental periods: (i) $\mathrm{J}_{20}$ of $13.3 \mathrm{LMH}$ and temperature of $33{ }^{\circ} \mathrm{C}$; (ii) $\mathrm{J}_{20}=10 \mathrm{LMH}$ and $\mathrm{T}=33{ }^{\circ} \mathrm{C}$; (iii) $\mathrm{J}_{20}=12 \mathrm{LMH}$ and $\mathrm{T}=25^{\circ} \mathrm{C}$; (iv) $\mathrm{J}_{20}=13.3 \mathrm{LMH}$ and $\mathrm{T}=20^{\circ} \mathrm{C}$; and $(\mathbf{v}) \mathrm{J}_{20}=11 \mathrm{LMH}$ and ambient temperature (spring and summer, from about 20 to $30^{\circ} \mathrm{C}$ ); and (vi) $\mathbf{J}_{20}=9 \mathrm{LMH}$ and ambient temperature (autumn and winter, from about 30 to $15^{\circ} \mathrm{C}$ ). 


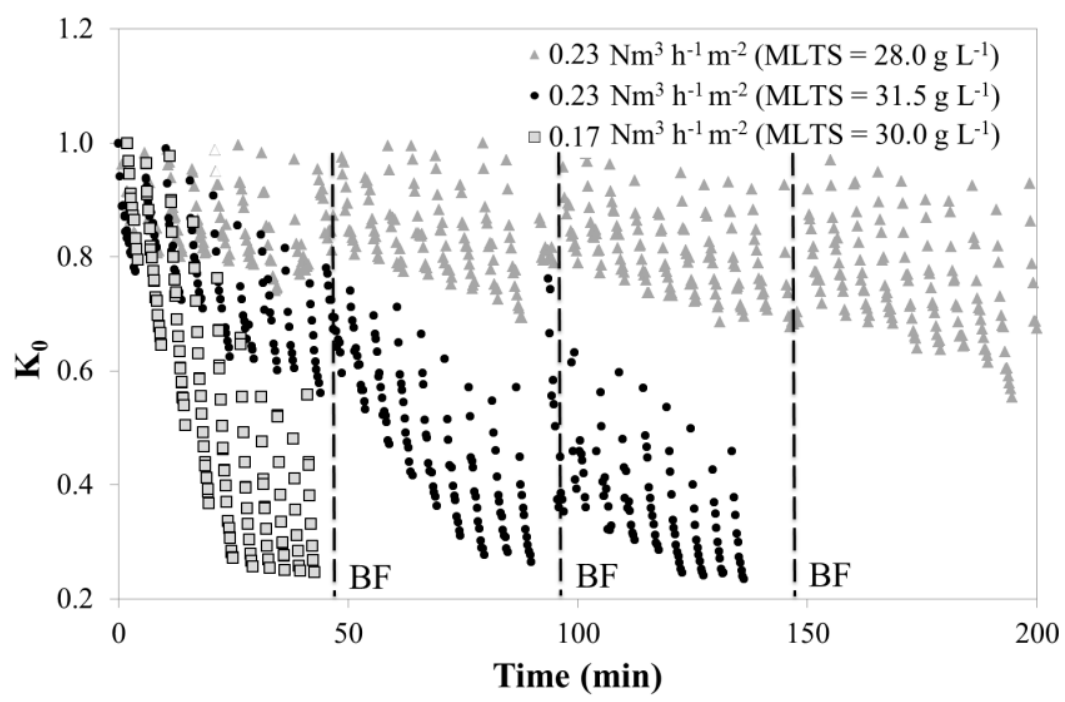

Figure 3. Short-term trial 1: Effect of gas sparging intensity on membrane permeability at MLTS level of 28, 30 and $31.5 \mathrm{~g} \mathrm{~L}^{-1}$. Nomenclature: MLTS: mixed liquor total solids; $\mathbf{K}_{\mathbf{0}}$ : unit-normalised membrane permeability; BF: back-flush. 


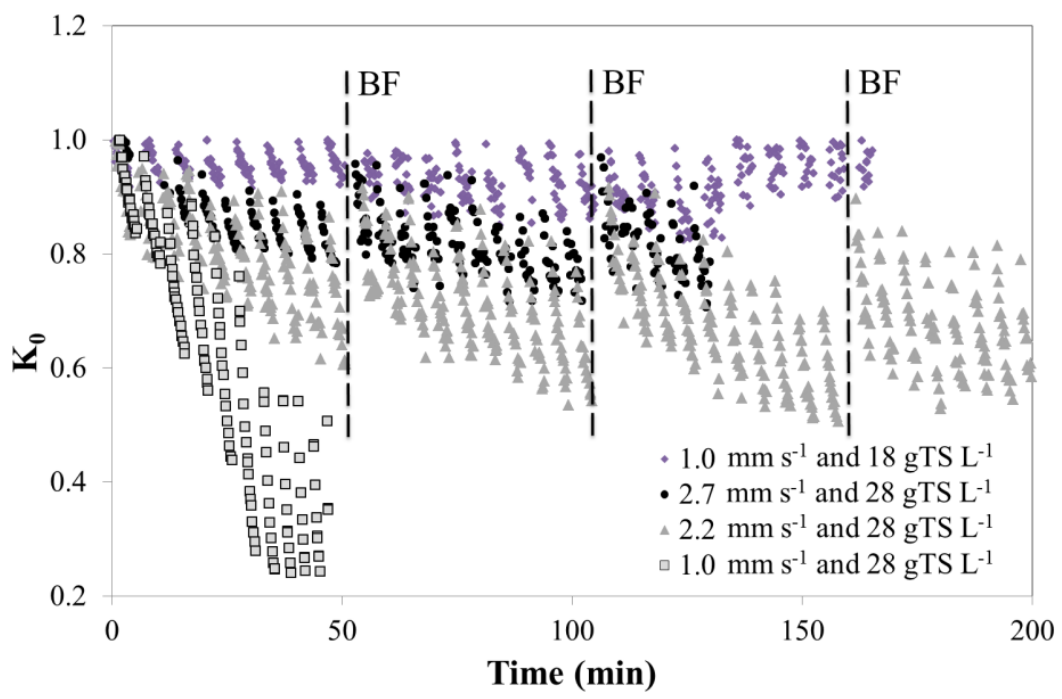

Figure 4. Short-term trial 2: Effect of up-flow sludge velocity on membrane permeability at MLTS levels of 18 and $28 \mathrm{~g} \mathrm{~L}^{-1}$, and up-flow sludge velocity of 1.0, 2.2, and $2.7 \mathrm{~mm} \mathrm{~s}^{-1}$. Nomenclature: MLTS: mixed liquor total solids; TS: total solids; $\mathbf{K}_{\mathbf{0}}$ : unit-normalised membrane permeability; $\mathbf{B F}$ : back-flush. 


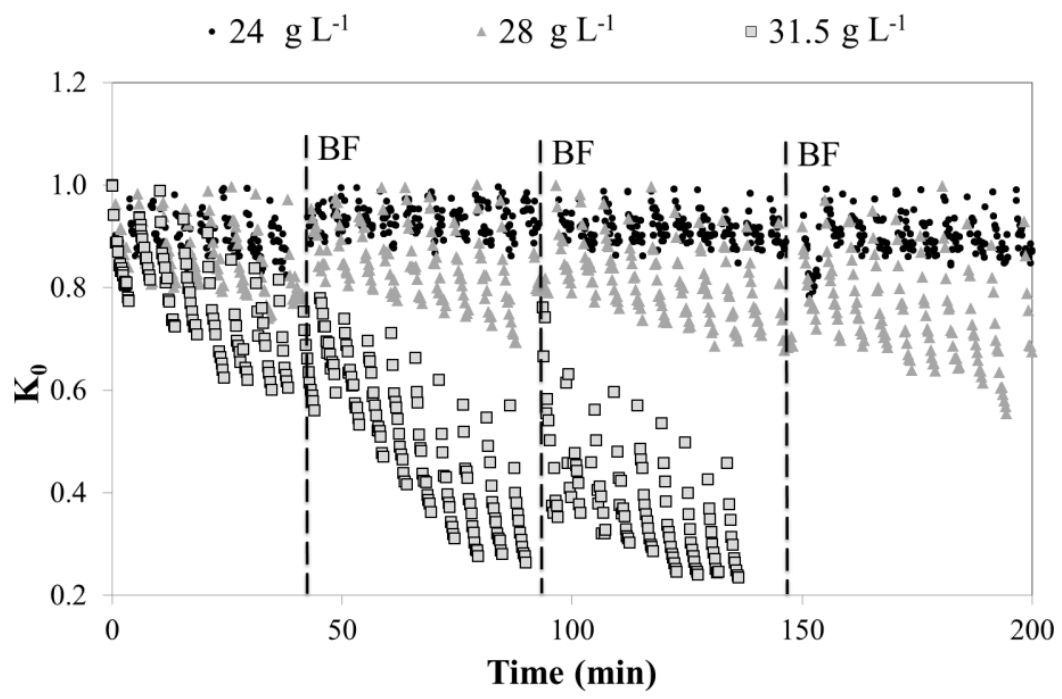

(a)

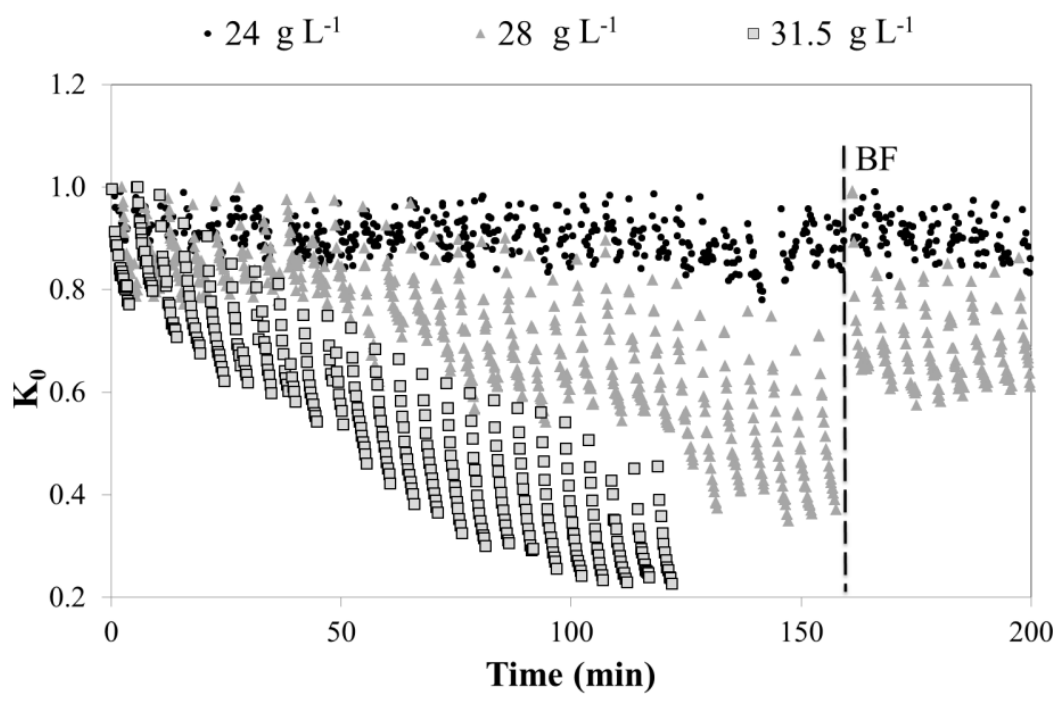

(b)

Figure 5. Short-term trial 3: Effect of back-flush frequency on membrane permeability at MLTS of 24, 28 and $31.5 \mathrm{~g} \mathrm{~L}^{-1}$ and (a) 30 seconds of back-flush every $10 \mathrm{~F}-\mathrm{R}$ cycles; and (b) 30 seconds of back-flush every 30 F-R cycles. Nomenclature: $\mathbf{K}_{\mathbf{0}}$ : unit-normalised membrane permeability; BF: back-flush. 
Figure 6

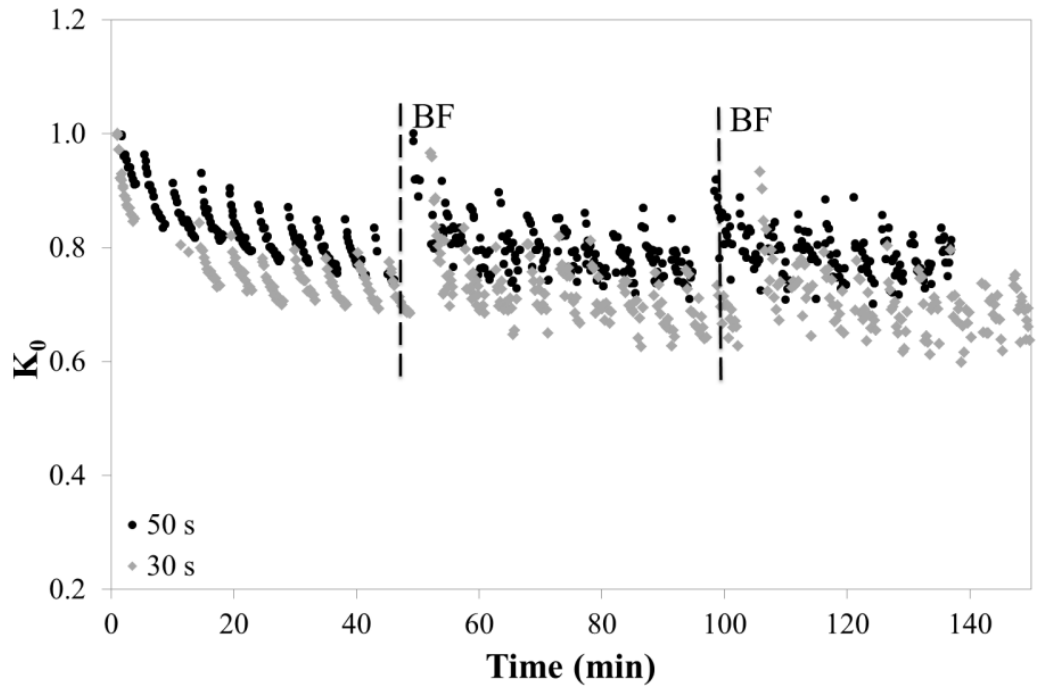

Figure 6. Short-term trial 4: Effect of relaxation stage duration on membrane permeability at MLTS level of $28 \mathrm{~g} \mathrm{~L}^{-1}$. Nomenclature: $\mathbf{K}_{\mathbf{0}}$ : unit-normalised membrane permeability; BF: back-flush. 


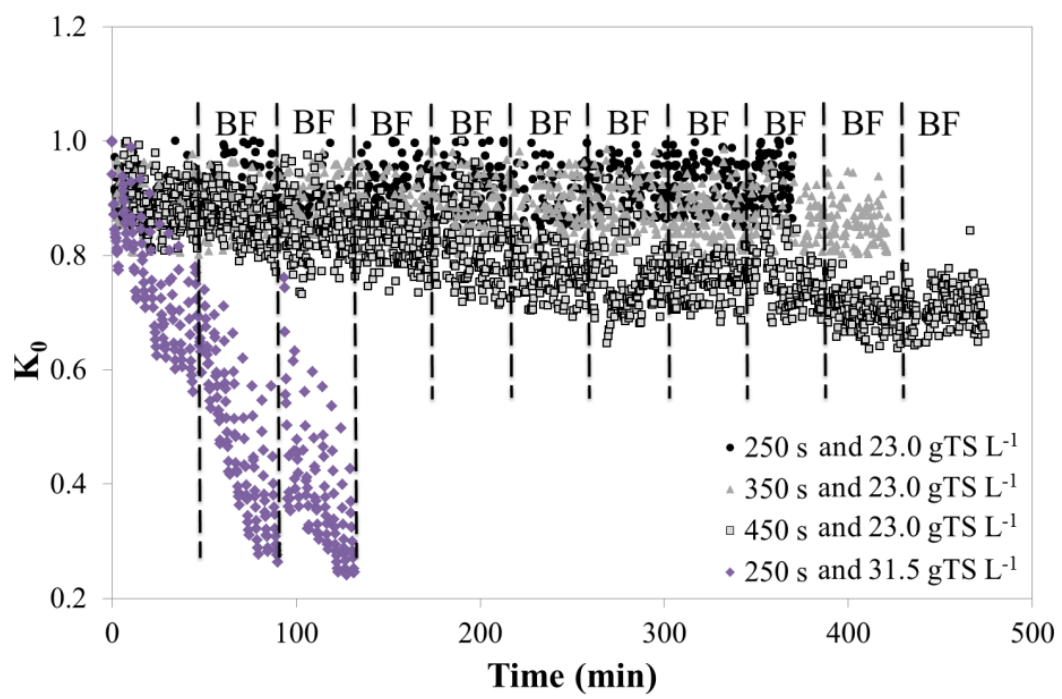

(a)

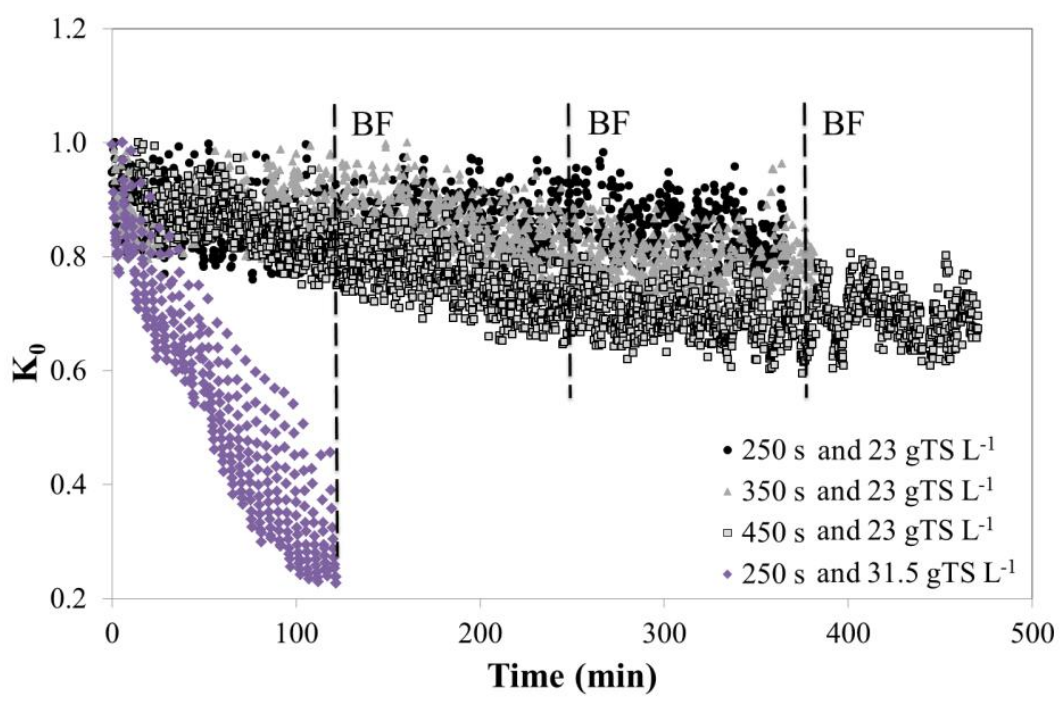

(b)

Figure 7. Short-term trial 5: Effect of filtration stage duration on membrane permeability at (a) MLTS levels of 23 and $31.5 \mathrm{~g} \mathrm{~L}^{-1}$ and back-flush frequency of 1 back-flush every 10 F-R cycles; and (b) MLTS levels of 23 and $31.5 \mathrm{~g} \mathrm{~L}^{-1}$ and back-flush frequency of 1 back-flush every $30 \mathrm{~F}-\mathrm{R}$ cycles. Nomenclature: $\mathbf{K}_{\mathbf{0}}$ : unit-normalised membrane permeability; $\mathbf{B F}$ : back-flush. 